\title{
Excessive daytime sleepiness in type 2 diabetes
}

Sonolência excessiva diurna em diabetes tipo 2

Camila Medeiros', Veralice Bruin', Débora Férrer', Ticiana Paiva', Renan Montenegro Júnior', Adriana Forti', Pedro Bruin'

\begin{abstract}
Objective: To examine excessive daytime sleepiness (EDS) in type 2 diabetes. Subjects and methods: Patients $(N=110)$ were evaluated regarding Epworth Sleepiness Scale (EDS), sleep quality (Pittsburgh Sleep Quality Index), depressive symptoms (Beck Depression Inventory), Restless Legs Syndrome (RLS), risk of obstructive sleep apnea (OSA) (Berlin questionnaire), and comorbidity severity (Charlson Comorbidity Index). Patients were compared with individuals with arterial hypertension and without diabetes. Results: Diabetic patients had more EDS, depressive symptoms, and higher comorbidity severity than hypertensive patients $(p<0.005)$. In diabetic patients, poor quality sleep (53.3\%), and high risk of OSA $(40.9 \%)$ and RLS (14.5\%) were found; EDS (55.5\%) was associated with depressive symptoms present in $44.5 \%$ individuals (OR $=1.08 ; 95 \% \mathrm{Cl}: 1.01-1.15)$, and remained so after data were controlled for age, gender, body mass index, and glycated hemoglobin (OR $=2.27 ; 95 \% \mathrm{Cl}$ 1.03-5.03). Conclusions: Sleep abnormalities are frequent. EDS affects most of the patients and is independently associated with depressive symptoms. Adequate antidepressant therapy should be tested for the effects on EDS. Arq Bras Endocrinol Metab. 2013;57(6):425-30
\end{abstract}

Keywords

Diabetes; sleep; depression; apnea; comorbidity

\section{RESUMO}

Objetivo: Em pacientes com diabetes tipo 2, avaliar a sonolência excessiva diurna (SED). Sujeitos e métodos: Pacientes ( $N=110$ ) foram investigados com relação a Escala de Sonolência de Epworth (SED), qualidade do sono (Índice de Qualidade de Sono Pittsburgh), sintomas depressivos (Inventário de Depressão de Beck), Síndrome das Pernas Inquietas (SPI), risco de apneia obstrutiva do sono (AOS) (Questionário de Berlim) e comorbidades (Índice de Comorbidade de Charlson), e foram comparados com indivíduos com hipertensão arterial sem diabetes. Resultados: Pacientes diabéticos apresentavam mais SED, sintomas depressivos e comorbidades que os hipertensos $(p<0,005)$. Em pacientes diabéticos, má qualidade do sono $(53,3 \%)$, risco de AOS $(40,9 \%)$ e SPI $(14,5 \%)$ foram encontrados. SED $(55,5 \%)$ associou-se com os sintomas depressivos em 44,5\% (OR = 1,08; 95\% IC 1,01-1,15) e permaneceu após controle para idade, sexo, índice de massa corporal e hemoglobina glicosilada (OR = 2,27 95\% IC 1,03-5,03). Conclu. sões: Anormalidades do sono são frequentes. SED afeta a maioria dos pacientes e associa-se de forma independente com os sintomas depressivos. Terapia antidepressiva pode melhorar a SED. Arq Bras Endocrinol Metab. 2013;57(6):425-30

\section{Descritores}

Diabetes; sono; depressão; apneia; comorbidade
Faculdade de Medicina Universidade Federal do Ceará (UFC), Fortaleza, CE, Brazil

Correspondence to: Veralice Bruin Rua Coronel Nunes de Melo, 1315 60430-270 - Fortaleza, CE, Brazil veralice@superig.com.br

Received on Mar/13/2013 Accepted on May/29/2013 


\section{INTRODUCTION}

$\mathrm{D}$ aytime somnolence and inattention are potential causes for accidents, cognitive decline, and reduced work efficiency (1). Previous studies have linked sleepiness with higher morbidity and mortality rates in various clinical settings $(2,3)$. Increasing attention has been paid to the connection between diabetes and excessive daytime sleepiness $(4,5)$. It has been suggested that diabetic patients are more likely to be sleepy during the daytime than non-diabetic ones $(6,7)$; moreover, greater risk for traffic accidents due to somnolence has been shown in diabetic patients (8). It has also been found that sleepiness is associated with a general decrease in motivation to engage in activities that are important in the management of diabetes (5).

Despite the recognition of sleepiness as a major public health issue (9), its clinically associated factors and pathogenesis have not been totally clarified. Previous studies indicate that, among the general population, excessive daytime sleepiness has been more strongly associated with depression and obesity than with metabolic factors, sleep-disordered breathing, or sleep disruption $(10,11)$. Interestingly, in elderly people, sleep alterations have been associated with depression, cognitive decline, and diabetes (12). It has also been pointed out that increased daytime sleepiness does not seem to be driven only by the presence of obstructive sleep apnea (OSA). In fact, a study has suggested that several clinical factors such as obesity, metabolic abnormalities, or inflammatory markers may play a role in the genesis of excessive daytime sleepiness (13). Therefore, increased daytime sleepiness in type 2 diabetes may be associated with sleep disorders such as OSA (14), insomnia (15), and restless legs syndrome (16). After considering all the above, understanding the associations between sleep disorders and daytime somnolence in type 2 diabetes may contribute to therapy in these patients.

The aim of this study was to evaluate excessive daytime sleepiness in type 2 diabetes and its associations with depressive symptoms, other sleep complaints, and clinical/laboratory variables.

\section{MATERIALS AND METHODS}

\section{Study design and participants}

This is a cross-sectional study of individuals with type 2 diabetes. We evaluated 113 consecutive men and women with type 2 diabetes who presented for clini- cal follow-up in an outpatient diabetes clinic. Three subjects refused to answer the questionnaires and were withdrawn from the sample. Inclusion criteria were the diagnosis of type 2 diabetes, clinical stability, and no change of medication in the previous three months. Exclusion criteria were working in the night shift, history of alcohol or drug abuse, presence of cancer or of severe neurologic, renal, or cardiac diseases. Data from diabetic patients were compared with a group of patients with arterial hypertension and without diabetes $(\mathrm{n}=$ 36). The protocol was approved by the local Research Ethics Committee, and written informed consent was obtained for all subjects (CEP/HUWC 031.04.09).

\section{Outcome measures}

Demographic data, habits, and comorbidities were recorded using a standardized questionnaire. Biochemical data were collected from patient files. Body mass index (BMI) was calculated as the ratio between weight $(\mathrm{kg})$ and squared height $\left(\mathrm{m}^{2}\right)$. Daytime somnolence was assessed by the Epworth Sleepiness Scale (ESS), a questionnaire containing eight items that ask about the expectation of dozing in eight hypothetical situations. Epworth Sleepiness Scale score greater than 10 indicates excessive daytime sleepiness (17). Subjective sleep quality was evaluated by the Pittsburgh Sleep Quality Index (PSQI). Pittsburgh Sleep Quality Index has seven components, each one dealing with a major aspect of sleep: subjective quality of sleep, sleep onset latency, sleep duration, sleep efficiency, and presence of sleep disturbances. Individuals with total PSQI score greater than six were considered poor sleepers (18). Depressive symptoms were evaluated by the Beck Depression Inventory (BDI), and were defined as present if the score was greater than 10 (19). Frequent associated comorbidities, such as hypertension, high risk of OSA, and restless legs syndrome, which might influence excessive daytime sleepiness, were analyzed. Restless leg syndrome was identified using the minimum criteria defined by the International Restless Legs Syndrome Study Group: 1) an urge to move the legs, usually accompanied or caused by uncomfortable and unpleasant sensations in the legs; 2) the urge to move or the beginning or worsening of unpleasant sensations happening during periods of rest or inactivity, such as lying or sitting; 3 ) the urge to move or unpleasant sensations being partially or totally relieved by movement, such as walking or stretching, at least as long as the activity continues; and 4 ) the urge to move or unpleasant sensations being 
worse in the evening or night than during the day, or occuring only in the evening or night (20). This scale has been adapted to Brazilian patients (21). Risk of having OSA were assessed by the Berlin questionnaire (22). In order to assess the influence and presence of associated comorbidities, the Charlson Comorbidity Index (CCI) was used (23).

\section{Statistical analysis}

Data are expressed as mean \pm SD values. Comparisons between diabetic patients and subjects with arterial hypertension and without diabetes were performed. Diabetic patients were grouped as having excessive daytime sleepiness or not. Fisher exact tests for categorical variables, Mann-Whitney $U$ test for continuous variables, and Student's t test for normally distributed data with equal variances were performed to compare cases and controls. Logistic regression analysis was used to examine associations between clinical and demographic variables, and excessive daytime sleepiness. Posterior adjustments for age, gender, BMI and glycated hemoglobin were performed. Statistical analysis was performed with the Statistic Package for Social Sciences (SPSS - Norusis, 1993) software for Windows. The level of significance was set at $\mathrm{p}<0.05$.

\section{RESULTS}

A total of 110 type 2 diabetes patients, $73(65.8 \%)$ females with a mean age of $57.6 \pm 11.0$ years and 36 individuals with arterial hypertension, 21 (58.3\%) female, mean age $57.6 \pm 9.7$ were studied. Patients with diabetes showed greater comorbidity severity as evaluated by the CCI, more depressive symptoms as evaluated by the $\mathrm{BDI}$, and more severe excessive daytime sleepiness $(\mathrm{p}<$ $0.005)$. Subjects with arterial hypertension had worse sleep quality as evaluated by the PSQI $(\mathrm{p}<0.005)$ (Table 1). In diabetic patients, excessive daytime sleepiness was present in $55.5 \%$ of cases. This was not related to gender, age, disease duration, BMI, waist-hip ratio, and laboratory results (Table 2). Diabetic patients with excessive daytime sleepiness showed significantly higher BDI scores than non-diabetic patients $(11.43 \pm 6.79 \mathrm{vs}$. $8.43 \pm 6.0, \mathrm{p}=0.01$, respectively). An association between excessive daytime sleepiness and depressive symptoms was found $(\mathrm{OR}=1.08 ; 95 \% \mathrm{CI}: 1.01-1.15)$, and remained significant after data were controlled for age, gender, BMI, and glycated hemoglobin $(\mathrm{OR}=2.27$; 95\% CI: 1.03-5.03) (Table 3). In diabetic patients, poor sleep quality was found in $53.3 \%$ of the cases, and was not associated with daytime sleepiness. Restless leg syndrome was found in $14.5 \%$ of the cases and arterial hypertension in $70.0 \%$; neither was associated with excessive daytime sleepiness. The risk of OSA, as defined by the Berlin questionnaire, was present in $40.9 \%$ of the patients, and was not associated with excessive daytime sleepiness. Comorbidity severity as evaluated by the CCI was not associated with excessive daytime sleepiness. The most common complications associated with diabetes were peripheral neuropathy $(31.2 \%)$, retinopathy $(17.8 \%)$, cataract $(19.0 \%)$, and renal disease (5.4\%). Depressive symptoms were present in $44.5 \%$ of diabetic patients and were associated with poor sleep quality as evaluated by the PSQI $(\mathrm{OR}=1.39 ; 95 \% \mathrm{CI}$ : 1.21-1.59).

Table 1. Demographic characteristics and clinical factors of subjects with diabetes and hypertension

\begin{tabular}{lccc}
\hline & Diabetes & Hypertension & $\boldsymbol{p}$ value \\
\hline Gender M/F & $38 / 72$ & $15 / 21$ & ${ }^{\mathrm{a}} 0.43$ \\
Age (years) & $57.59 \pm 11.04$ & $57.58 \pm 9.70$ & ${ }^{\mathrm{b}} 0.99$ \\
BMl & $27.55 \pm 4.79$ & $29.41 \pm 5.85$ & ${ }^{\mathrm{b}} 0.06$ \\
ESS & $10.72 \pm 5.81$ & $6.00 \pm 3.84$ & ${ }^{\mathrm{c}} 0.000^{\star *}$ \\
BDI & $10.09 \pm 6.59$ & $5.94 \pm 3.95$ & ${ }^{\mathrm{c}} 0.000^{\star *}$ \\
PSQl & $7.40 \pm 4.22$ & $15.00 \pm 7.82$ & ${ }^{\mathrm{c}} 0.000^{* *}$ \\
CCl & $2.24 \pm 1.59$ & $0.47 \pm 0.84$ & ${ }^{\mathrm{c}} 0.000^{\star \star}$ \\
Risk of OSA (Yes/No) & $45 / 65$ & $17 / 19$ & ${ }^{\mathrm{a}} 0.21$ \\
\hline
\end{tabular}

ESS: Epworth Sleepiness Scale; M/F: Male/Female; BMI: Body Mass Index; BDI: Beck Depression Inventory; PSQl: Pittsburgh Sleep Quality Index; CCl: Charlson Comorbidity Index; OSA: Obstructive Sleep Apnea.

a Fisher Exact Test; ${ }^{\circ}$ Student's Test; c Mann-Whitney Test.

Table 2. Clinical, laboratory, and demographic characteristics of subjects with and without excessive daytime sleepiness

\begin{tabular}{lccc}
\hline & $\begin{array}{c}\text { ESS } \leq \mathbf{1 0} \\
\mathbf{n}=\mathbf{4 9}\end{array}$ & $\begin{array}{c}\text { ESS }>\mathbf{1 0} \\
\mathbf{n = 6 1}\end{array}$ & $\begin{array}{c}\text { Unadjusted } \\
\mathbf{p} \text { value }\end{array}$ \\
\hline Gender M/F & $16 / 33$ & $22 / 39$ & ${ }^{\mathrm{a}} 0.84$ \\
Age (years) & $55.8 \pm 11.7$ & $58.89 \pm 10.38$ & ${ }^{\mathrm{b}} 0.14$ \\
BMI & $27.84 \pm 5.62$ & $27.28 \pm 4.00$ & ${ }^{\mathrm{b}} 0.55$ \\
Waist-hip ratio (cm) & $0.93 \pm 0.09$ & $0.93 \pm 0.06$ & ${ }^{\mathrm{b}} 0.79$ \\
Disease duration (years) & $10.10 \pm 7.94$ & $10.53 \pm 7.29$ & ${ }^{\mathrm{b}} 0.80$ \\
Hemoglobin (g/dL) & $12.79 \pm 3.06$ & $13.03 \pm 1.79$ & ${ }^{\mathrm{b}} 0.74$ \\
Glycated hemoglobin (\%) & $8.83(2.77)$ & $8.71(2.63)$ & ${ }^{\mathrm{b}} 0.85$ \\
Cholesterol (mg/dL) & $200.5 \pm 42.1$ & $204.5 \pm 43.2$ & ${ }^{\mathrm{b}} 0.72$ \\
Triglycerides (mg/dL) & $526.5 \pm 172.3$ & $315.0 \pm 118.3$ & ${ }^{\mathrm{b}} 0.43$ \\
HDL (mg/dL) & $39.3 \pm 12.3$ & $43.3 \pm 10.1$ & ${ }^{\mathrm{b}} 0.12$ \\
\hline
\end{tabular}

ESS: Epworth Sleepiness Scale; M/F: Male/Female; BMI: Body Mass Index; cm: centimeter; HDL: High Density Lipoprotein.

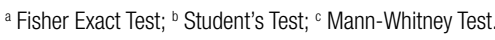


Table 3. Clinical factors associated with excessive daytime sleepiness based on multiple logistic regression analysis

\begin{tabular}{lcc}
\hline \multirow{2}{*}{ Model 1 } & \multicolumn{2}{c}{ Excessive daytime sleepiness } \\
\cline { 2 - 3 } & OR (95\%Cl) & p Value \\
\hline Beck Depression Inventory & $1.08(1.01-1.15)$ & $0.02^{*}$ \\
Pittsburgh Sleep Quality Index & $1.08(0.98-1.19)$ & 0.09 \\
Charlson Comorbidity Index & $1.19(0.91-1.55)$ & 0.18 \\
Restless Legs Syndrome & $1.32(0.45-3.83)$ & 0.60 \\
Hypertension & $1.38(0.60-3.18)$ & 0.44 \\
High risk of obstructive sleep apnea & $0.33(0.01-6.65)$ & 0.47 \\
(Berlin questionnaire) & & \\
\hline Model 2 & & \\
\hline Beck Depression Inventory & $2.27(1.03-5.03)$ & $0.04^{*}$ \\
Pittsburgh Sleep Quality Index & $1.10(0.96-1.25)$ & 0.15 \\
Charlson Comorbidity Index & $1.21(0.79-1.84)$ & 0.36 \\
Restless Legs Syndrome & $0.81(0.20-3.21)$ & 0.77 \\
Hypertension & $0.54(0.15-1.96)$ & 0.35 \\
High risk of obstructive sleep apnea & $1.02(0.97-1.06)$ & 0.42 \\
(Berlin questionnaire) & & \\
\hline
\end{tabular}

Model 1: In this unadjusted model, Beck Depression Inventory scores, Pittsburgh Sleep Quality Index scores, and Charlson Comorbidity Index scores were entered as numerical variables, and Restless Legs Syndrome, Hypertension, and High risk of obstructive sleep apnea as dichotomized variables (present/absent). Hosmer-Lemeshow goodness-of-fit tests showed 9.65 and $p \quad 0.29$ demonstrating a good fit of the models. Model 2: In this model, data was adjusted for age, gender, body mass index, and glycated hemoglobin.

\section{DISCUSSION}

These results show that excessive daytime sleepiness is common in type- 2 diabetes and affects more than half of the patients. Of crucial importance is the fact that excessive daytime sleepiness was independently associated with depressive symptoms. This is in agreement with previous reports showing that daytime somnolence is linked with depressive symptoms in the general population (10) and in the elderly (12). Differently from the study of Bixler and cols., metabolic abnormalities were not found to influence excessive daytime sleepiness in diabetic patients (10). By comparison, diabetic patients showed more sleepiness, more depressive symptoms, and higher comorbidity severity than patients with hypertension. Interestingly, hypertensive patients without diabetes had worse quality of sleep. These findings may be related to the association between obstructive sleep apnea and hypertension (24). With regards to the presence of daytime sleepiness, differences in BMI were not found. This is in contrast to a previous report showing that obesity is associated with objective and subjective daytime sleepiness regardless of the presence of sleep apnea (10). In this report, the risk for sleep apnea was the same for diabetic patients with and without excessive daytime sleepiness. Also, despite prior reports showing gender differences in excessive daytime sleepiness (25) and depressive symptoms (26), no gender differences were found in this study. Together, these findings suggest that depressive symptoms play an important role in the genesis of daytime somnolence in type 2 diabetes. We cannot exclude other so far non-established abnormalities, such as the presence of inflammation, in the pathogenesis of daytime sleepiness. It has been previously suggested that a bidirectional relationship between depression and inflammation exists. Depression can result in an up-regulation of inflammatory mediators that can further contribute to daytime sleepiness (27). Furthermore, it has been demonstrated that increases in sleep duration are associated with elevations in C-reactive protein and interleukin-6 (28). This is a subject that needs further clarification. Prospective studies could test the effects of antidepressants in daytime somnolence, cognitive function, reduced alertness, and driving ability (29).

We confirm that poor sleep quality affects more than half of diabetic patients (16). An association between depressive symptoms and poor quality of sleep was found. In another group of patients and, in agreement with our findings, it has been shown that among the obese, the level of emotional stress is the key distinguishing factor between good sleepers and poor sleepers (30). Of interest, depression and diabetes were the most important determinants of daytime sleepiness in a population with OSA (31). The connection between reduced sleep, sleep apnea, and the posterior risk of developing diabetes has been suggested before (32). Considering the endemic situation of chronic sleep loss in modern society, it should be noticed that this public health issue may be contributing to increase the prevalence of diabetes worldwide. All this indicates that a therapeutic approach of depressive symptoms may not only increase the level of daytime alertness and daily activities but also improve sleep disturbances and glycemic control. A recent placebo-controlled, single-blind study evaluating the effects of exenatide, a medication for the treatment of type 2 diabetes, has shown significant reduction in objective sleepiness in obese patients with type 2 diabetes without OSA. The same study showed no significant change in depression and driving performance (33).

In this study, we confirm that restless leg syndrome is frequent in type 2 diabetes (16). Restless leg syndrome was present in $14.5 \%$ of cases, which is twice the expected values for a large population-based study (34). 
Limitations of this study must be acknowledged. It was a cross-sectional evaluation, and a prospective study could clarify the effects of antidepressant on sleepiness in these patients. Also, sleepiness was a subjective measure, and objective measures of daytime sleepiness were not tested. The Multiple Sleep Latency test has been considered the gold standard objective method for sleepiness assessment (35). However, the ESS is used worldwide as a standard measure in the evaluation of excessive daytime sleepiness. Furthermore, it has been suggested that subjective measures and objective measures may assess different aspects of excessive daytime sleepiness (36): subjective sleepiness as evaluated by the ESS would mean a sleep dimension different from measures of objective sleepiness. Despite this controversy, ESS remains the most frequent used scale for the assessment of daytime sleepiness and therapeutic efficiency. It is worth noticing that the present data highlight the magnitude of daytime sleepiness and its association with depressive symptoms: these findings indicate the need to verify the potential modifying effects of antidepressants.

In summary, in diabetic patients, daytime somnolence is frequent and independently associated with depressive symptoms. We suggest that diabetic patients with excessive daytime sleepiness should be more thoroughly investigated for these symptoms. Proper therapy might improve alertness and psychological well-being leading to better cooperation and disease control.

Acknowledgements: this study was supported by the Conselho Nacional de Desenvolvimento Científico e Tecnológico (CNPq) and Fundação Cearense de Apoio ao Desenvolvimento Científico e Tecnológico (Funcap).

Disclosure: no potential conflict of interest relevant to this article was reported.

\section{REFERENCES}

1. Merlino G, Piani A, Gigli GL, Cancelli I, Rinaldi A, Baroselli A, et al. Daytime sleepiness is associated with dementia and cognitive decline in older Italian adults: a population-based study. Sleep Med. 2010;11(4):372-7.

2. Vgontzas AN, Bixler EO, Chrousos GP. Obesity-related sleepiness and fatigue: the role of the stress system and cytokines. Ann NY Acad Sci. 2006;1083:329-44.

3. Young T, Finn L, Peppard PE, Szklo-Coxe M, Austin D, Nieto FJ, et al. Sleep disordered breathing and mortality: eighteen-year follow-up of the Wisconsin sleep cohort. Sleep. 2008;31(8):1071-8.

4. Foley D, Monjan A, Masaki K, Ross W, Havlik R, White L, et al. Daytime sleepiness is associated with 3-year incident dementia and cognitive decline in older Japanese-American men. J Am Geriatr Soc. 2001;49(12):1628-32.
5. Chasens ER, Olshansky E. Daytime sleepiness, diabetes, and psychological well-being. Issues Ment Health Nurs. 2008;29(10):1134-50.

6. Chasens ER, Sereika SM, Burke LE. Daytime sleepiness and functional outcomes in older adults with diabetes. Diabetes Educ. 2009;35(3):455-64.

7. Asplund R. Daytime sleepiness and napping amongst the elderly in relation to somatic health and medical treatment. J Intern Med. 1996;239(3):261-7.

8. Hayashino Y, Yamazaki S, Nakayama T, Sokejima S, Fukuhara S. Relationship between diabetes mellitus and excessive sleepiness during driving. Exp Clin Endocrinol Diabetes. 2008;116(1):1-5.

9. Ronksley PE, Hemmelgarn BR, Heitman SJ, Flemons WW, Ghali WA, Manns B, et al. Excessive daytime sleepiness is associated with increased health care utilization among patients referred for assessment of OSA. Sleep. 2011;34(3):363-70.

10. Bixler EO, Vgontzas AN, Lin HM, Calhoun SL, Vela-Bueno A, Kales A. Excessive daytime sleepiness in a general population sample: the role of sleep apnea, age, obesity, diabetes, and depression. J Clin Endocrinol Metab. 2005;90(8):4510-5.

11. Pamidi S, Knutson KL, Ghods F, Mokhlesi B. Depressive symptoms and obesity as predictors of sleepiness and quality of life in patients with REM-related obstructive sleep apnea: crosssectional analysis of a large clinical population. Sleep Med. 2011;12(9):827-31.

12. Bonanni E, Tognoni G, Maestri M, Salvati N, Fabbrini M, Borghetti $D$, et al. Sleep disturbances in elderly subjects: an epidemiological survey in an Italian district. Acta Neurol Scand. 2010;122(6):389-97.

13. Dixon JB, Dixon ME, Anderson ML, Schachter L, O'Brien PE. Daytime sleepiness in the obese: not as simple as obstructive sleep apnea. Obesity (Silver Spring). 2007;15(10):2504-11.

14. Resnick HE, Redline S, Shahar E, Gilpin A, Newman A, Walter R, et al. Diabetes and sleep disturbances: findings from the Sleep Heart Health Study. Diabetes Care. 2003;26(3):702-9.

15. Eriksson AK, Ekbom A, Granath F, Hilding A, Efendic S, Ostenson CG. Psychological distress and risk of pre-diabetes and Type 2 diabetes in a prospective study of Swedish middle-aged men and women. Diabet Med. 2008;25(7):834-42.

16. Lopes LA, Lins Cde M, Adeodato VG, Quental DP, de Bruin PF, Montenegro RM Jr, et al. Restless legs syndrome and quality of sleep in type 2 diabetes. Diabetes Care. 2005;28(11):2633-6.

17. Johns MW. A new method for measuring daytime sleepiness: the Epworth sleepiness scale. Sleep. 1991;14(6):540-5.

18. Buysse DJ, Reynolds CF 3rd, Monk TH, Berman SR, Kupfer DJ. The Pittsburgh Sleep Quality Index: a new instrument for psychiatric practice and research. Psychiatry Res. 1989;28(2):193-213.

19. Beck AT, Steer RA. Internal consistencies of the original and revised Beck Depression Inventory. J Clin Psychol. 1984;40(6):1365-7.

20. Allen RP, Picchietti D, Hening WA, Trenkwalder C, Walters AS, Montplaisi J. Restless legs syndrome: diagnostic criteria, special considerations, and epidemiology. A report from the restless legs syndrome diagnosis and epidemiology workshop at the National Institutes of Health. Sleep Med. 2003;4(2):101-19.

21. Masuko AH, Carvalho LB, Machado MA, Morais JF, Prado LB, Prado GF. Translation and validation into the Brazilian Portuguese of the restless legs syndrome rating scale of the International Restless Legs Syndrome Study Group. Arq Neuropsiquiatr. 2008;66(4):832-6.

22. Netzer NC, Stoohs RA, Netzer CM, Clark K, Strohl KP. Using the Berlin Questionnaire to identify patients at risk for the sleep apnea syndrome. Ann Intern Med. 1999;131(7):485-91.

23. Charlson ME, Pompei P, Ales KL, MacKenzie CR. A new method of classifying prognostic comorbidity in longitudinal studies: development and validation. J Chronic Dis. 1987;40(5):373-83. 
24. Farias PAMdF, Lima AMA, Bruin PFCd, Bruin VMS. Sleep-disordered breathing and heavy drinking: clinical features and polysomnographic findings. Sleep Science. 2010;3(4):119-24.

25. Hublin C, Kaprio J, Partinen M, Heikkila K, Koskenvuo M. Daytime sleepiness in an adult, Finnish population. J Intern Med. 1996;239(5):417-23.

26. Chiu CJ, Wray LA. Gender differences in functional limitations in adults living with type 2 diabetes: biobehavioral and psychosocial mediators. Ann Behav Med. 2011;41(1):71-82.

27. Raison CL, Capuron L, Miller AH. Cytokines sing the blues: inflammation and the pathogenesis of depression. Trends Immunol. 2006;27(1):24-31.

28. Patel SR, Zhu X, Storfer-lsser A, Mehra R, Jenny NS, Tracy R, et al. Sleep duration and biomarkers of inflammation. Sleep. 2009;32(2):200-4.

29. da Silva-Junior FP, de Pinho RS, de Mello MT, de Bruin VM, de Bruin PF. Risk factors for depression in truck drivers. Soc Psychiatry Psychiatr Epidemiol. 2009;44(2):125-9.

30. Vgontzas AN, Bixler EO, Chrousos GP, Pejovic S. Obesity and sleep disturbances: meaningful sub-typing of obesity. Arch Physiol Biochem. 2008;114(4):224-36.
31. Koutsourelakis I, Perraki E, Bonakis A, Vagiakis E, Roussos C, Zakynthinos $S$. Determinants of subjective sleepiness in suspected obstructive sleep apnoea. J Sleep Res. 2008;17(4):437-43.

32. Reichmuth KJ, Austin D, Skatrud JB, Young T. Association of sleep apnea and type II diabetes: a population-based study. Am J Respir Crit Care Med. 2005;172(12):1590-5.

33. Idris I, Abdulla H, Tilbrook S, Dean R, Ali N. Exenatide improves excessive daytime sleepiness and wakefulness in obese patients with type 2 diabetes without obstructive sleep apnoea. J Sleep Res. 2013;22(1):70-5.

34. Ulfberg J, Bjorvatn B, Leissner L, Gyring J, Karlsborg M, Regeur $L$, et al. Comorbidity in restless legs syndrome among a sample of Swedish adults. Sleep Med. 2007;8(7-8):768-72.

35. Johns MW. Sensitivity and specificity of the multiple sleep latency test (MSLT), the maintenance of wakefulness test and the epworth sleepiness scale: failure of the MSLT as a gold standard. J Sleep Res. 2000;9(1):5-11.

36. Benbadis SR, Mascha E, Perry MC, Wolgamuth BR, Smolley LA, Dinner DS. Association between the Epworth sleepiness scale and the multiple sleep latency test in a clinical population. Ann Intern Med. 1999;130(4 Pt 1):289-92. 